Research Article

\title{
Prevalence and Phenotypic and Genotypic Resistance Mechanisms of Multidrug-Resistant Pseudomonas aeruginosa Strains Isolated from Clinical, Environmental, and Poultry Litter Samples from the Ashanti Region of Ghana
}

\author{
Hayford Odoi $\mathbb{D}^{1},{ }^{1}$ Vivian Etsiapa Boamah $\mathbb{D}^{2},{ }^{2}$ Yaw Duah Boakye $\mathbb{D}^{2}$, \\ and Christian Agyare $\mathbb{1}^{2}$ \\ ${ }^{1}$ Department of Pharmaceutical Microbiology, School of Pharmacy, University of Health and Allied Sciences, Ho, Volta Region, \\ Ghana \\ ${ }^{2}$ Department of Pharmaceutics, Faculty of Pharmacy and Pharmaceutical Sciences, \\ Kwame Nkrumah University of Science and Technology, Kumasi, Ghana
}

Correspondence should be addressed to Christian Agyare; chrisagyare@yahoo.com

Received 4 March 2021; Accepted 3 June 2021; Published 16 June 2021

Academic Editor: Arun S. Kharat

Copyright (C) 2021 Hayford Odoi et al. This is an open access article distributed under the Creative Commons Attribution License, which permits unrestricted use, distribution, and reproduction in any medium, provided the original work is properly cited.

Background. Antibiotic resistance in bacteria is a major global health challenge. Reports on the prevalence of multidrug-resistant $P$. aeruginosa, a common pathogenic bacterium implicated in nosocomial infections and poultry diseases, are limited in Ghana. This study therefore sought to determine the prevalence of $P$. aeruginosa from hospitals, poultry farms, and environmental samples from the Ashanti region of Ghana. Methodology. Stool, urine, and blood samples from 364 patients from two hospitals in the Ashanti region of Ghana were randomly sampled. P. aeruginosa was isolated and confirmed using routine selective media and PCR-based oprL gene amplification. The Kirby-Bauer disk diffusion method employing EUCAST breakpoint values was used to identify multidrugresistant strains. The occurrence of common antibiotic inactivating enzymes and resistance encoding genes and the assessment of strain efflux capacity were investigated with double disc synergy test (DDST), imipenem-EDTA synergy test, phenylboronic acid test, D-test, routine PCR, and ethidium bromide agar-cartwheel method. Results. A total of $87(9.7 \%, n=87 / 900)$ P. aeruginosa isolates were confirmed from the samples. $75 \%(n=65 / 87)$ were resistant to more than one group of antipseudomonal agents, while $43.6 \%$ ( $n=38 / 87)$ were multidrug-resistant (MDR). High prevalence of extended spectrum $\beta$-lactamases $(84.2 \%)$, metallo- $\beta$-lactamases (34.1\%), and AmpC inducible cephalosporinases (50\%) was observed in the MDR strains. About 57.8\% of the MDR strains showed moderate to very high efflux capacity. Class 1 integrons were detected in $89.4 \%$ of the MDR isolates but $\beta$-lactamase encoding genes $\left(b l a_{S H V}, b l a_{T E M}, b l a_{C T X-M}, b l a_{V I M}\right.$, and $\left.b l a_{I M P}\right)$ were not detected. Conclusion. Surveillance of antibiotic-resistant strains of bacteria should be routinely conducted in clinical and veterinary practice in Ghana to inform selection of antibiotics for therapeutic use.

\section{Introduction}

The emergence and spread of multiple drug-resistant pathogenic bacteria is a major global health concern [1]. The natural resistome of bacteria and human influences on antibiotic use are contributory factors in the evolution of resistant bacteria [2]. The increased use of antibiotics in clinical, environmental, and agricultural settings has become pivotal in the selection and spread of resistant bacteria [3].
The evolution of resistance in bacteria may be due to $\mathrm{mu}$ tational events introduced during bacteria replication and vertical transmission of genetic variants through generations in a particular bacteria strain [4]. Accessory genetic elements carrying antibiotic resistance determinants (plasmids, integrons, and transposons) may also be disseminated horizontally in bacteria leading to wide spread of resistance [5]. In Ghana, antibiotics are easily accessible for prophylactic and metaphylactic purposes as well as for growth 
promotion in animal husbandry [6]. Prescribing of large doses of broad-spectrum antibiotics, nonadherence to prescribed doses, and long durations of antibiotic treatments in district and regional hospitals in the country have enhanced the evolution of drug-resistant strains in pathogenic bacteria [7]. According to a study by Newman et al. [8], Pseudomonas species were the second most prevalent (14.0\%) bacteria isolated during a six-month nationwide clinical surveillance study in Ghana. P. aeruginosa, a ubiquitous pathogen, is implicated in some nosocomial infections in patients [9]. It also causes pseudomoniasis, an opportunistic infection in poultry birds like chickens, turkeys, ducks, geese, and ostriches, where infection in eggs kills embryos [10]. P. aeruginosa is intrinsically resistant to many antimicrobial agents presenting clinicians with a great challenge during therapy. Several multidrug-resistant strains have been identified in many environmental niches from several countries [11]. $\beta$-lactam antibiotics, carbapenems, aminoglycosides, and quinolones play vital roles in the treatment of $P$. aeruginosa infections. However, multiple resistance of $P$. aeruginosa to these classes of antibiotics is on the surge. Resistance against these groups of antibiotics is influenced by varied resistance mechanisms. Predominant of these is the hydrolytic and inactivating activity of antibiotic degrading enzymes such as $\beta$-lactamases and aminoglycoside modifying enzymes [11], coupled with efficient efflux porins and external biofilm matrix. Mutations in the quinolone resistance determining region (QRDR) of DNA gyrase and topoisomerase IV alter the structural binding site of quinolones and thus confer reduced susceptibility. Reports on the prevalence of multidrug $P$. aeruginosa isolates and antibiotic resistance determinants in resistance-selection prone environments such as hospitals, animal farms, and sewages in Ghana are limited. The study therefore sought to determine the occurrence of $P$. aeruginosa strains and the prevalence of common antibiotic inactivating enzymes, mobile genetic elements (integrons), and resistance encoding genes in $P$. aeruginosa from selected poultry farms, hospitals, and market environments in Kumasi, Ghana.

\section{Methods}

2.1. Ethical Clearance/Approval. Ethical clearance for the study was obtained from the Committee on Human Research Publications and Ethics (CHRPE), Kwame Nkrumah University of Science and Technology (KNUST), Kumasi, Ghana. In addition, written consents were obtained from patients, farm managers, and workers and all participants in the study.

2.2. Study Sites, Subjects, and Sampling. The study was performed in Ashanti region in the central part of Ghana, located between $0.15-2.251 \mathrm{~W}$ and 5.50-7.46 N (Figure 1(a)). The region shares boundaries with five of the 16 political regions of Ghana. The region covers a total land area of $24,389 \mathrm{~km}^{2}$, representing $10.2 \%$ of the total land area of Ghana. 2 hospitals, namely, Suntreso Government Hospital and Kwame Nkrumah University of Science and Technology
(KNUST) Hospital, 137 poultry farms (Figure 1(b)), 1 public market (Kumasi central market), and Ayigya town, all located in Kumasi in Ashanti region of Ghana (Figure 1(c)), were selected for the study. Kumasi central market was selected because the market has a high population of traders and is the point of sale for most agricultural products from most parts of the region. Stool, urine, and blood samples from 364 patients were randomly sampled from the two hospitals. A total of 276 poultry litter samples were collected from 137 poultry farms in the Ashanti region of Ghana. All the samples were collected between September 2015 and July 2016 as part of routine AMR surveillance [12]. Swabs of community-based latrines, market floors and tables, soil, and sewage were also carried out for P. aeruginosa isolation.

2.3. Isolation and Identification of P. aeruginosa. Bacteria in the various samples collected were revived in soybean-casein-digest broth (Thermo Fisher Scientific, Waltham, MA, USA) and isolated on cetrimide agar (Thermo Fisher Scientific, Waltham, MA, USA). Preliminary identification was then conducted through Gram staining test for catalase and oxidase activities, haemolysin production, and growth at $42^{\circ} \mathrm{C}$. Production of pyocyanin, pyomelanin, pyorubin, and pyoverdine pigments was examined by culturing the isolates on Pseudomonas isolation agar (Alpha Biosciences, Baltimore, MD, USA). The isolates were confirmed by amplification of the species-specific outer membrane lipoprotein gene oprL (Figure 2) which provides confirmation for all phenotypes of this species [13]. With $0.6 \mu \mathrm{L}$ each of a $10 \mu \mathrm{M}$ forward primer [oprL-F (5'-ATG GAA ATG CTG AAA TTC GGC-3')] and reverse primer [oprL-R (5'-CTT CTT CAG CTC GAC GCG ACG-3')], polymerase chain reaction was carried out using a thermal cycler (GeneAmp, Thermo Fisher Scientific, Waltham, MA, USA) in a final volume of $25 \mu \mathrm{L}$ containing $2 \mu \mathrm{L}$ of DNA template, $12.5 \mu \mathrm{L}$ of GoTaq Master Mix (Promega, Madison, WI, USA), $0.75 \mu \mathrm{L}$ of a $0.5 \mathrm{mM}$ magnesium chloride, and $8.55 \mu \mathrm{L}$ of nuclease-free water. The DNA template was initially denatured at $94^{\circ} \mathrm{C}$ for $5 \mathrm{~min}$, followed by 35 cycles of denaturation at $94^{\circ} \mathrm{C}$ for $30 \mathrm{sec}$, annealing at $64^{\circ} \mathrm{C}$ for $30 \mathrm{sec}$, and extension at $72^{\circ} \mathrm{C}$ for $1 \mathrm{~min}$. Finally, the products were extended at $72^{\circ} \mathrm{C}$ for $10 \mathrm{~min}$. The PCR products were examined on a $2 \% \mathrm{w} / \mathrm{v}$ agarose gel at $60 \mathrm{~V}$ and visualized using a transilluminator (Fotodyne, Hartland, WI, USA).

2.4. Antibiotic Susceptibility Testing. Multidrug-resistant $P$. aeruginosa isolates were determined by determining the susceptibility of the $P$. aeruginosa isolates to selected antipseudomonal antibiotics using the Kirby-Bauer disk diffusion technique. The susceptibility tests were done in triplicate according to approved methods of the European Committee on Antimicrobial Susceptibility Testing [14]. To ensure a good representation of the isolates in the culture, about 5 to 7 well-separated colonies were picked and suspended in $5 \mathrm{~mL}$ sterile distilled water and vortexed at high speed until the suspension was uniform. The turbidity of the suspension of $P$. aeruginosa isolates was determined using a nephelometer already calibrated to $0.5 \mathrm{McFarland}$. The 


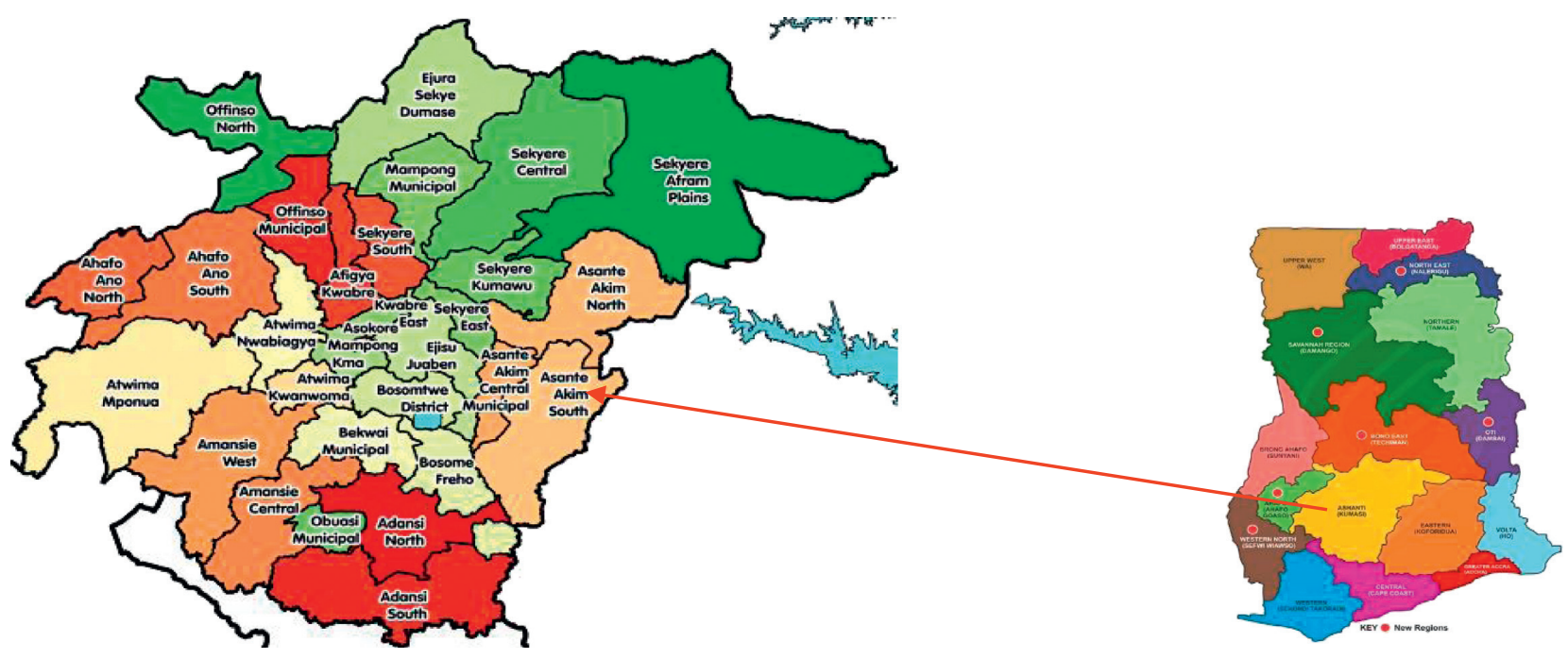

(a)

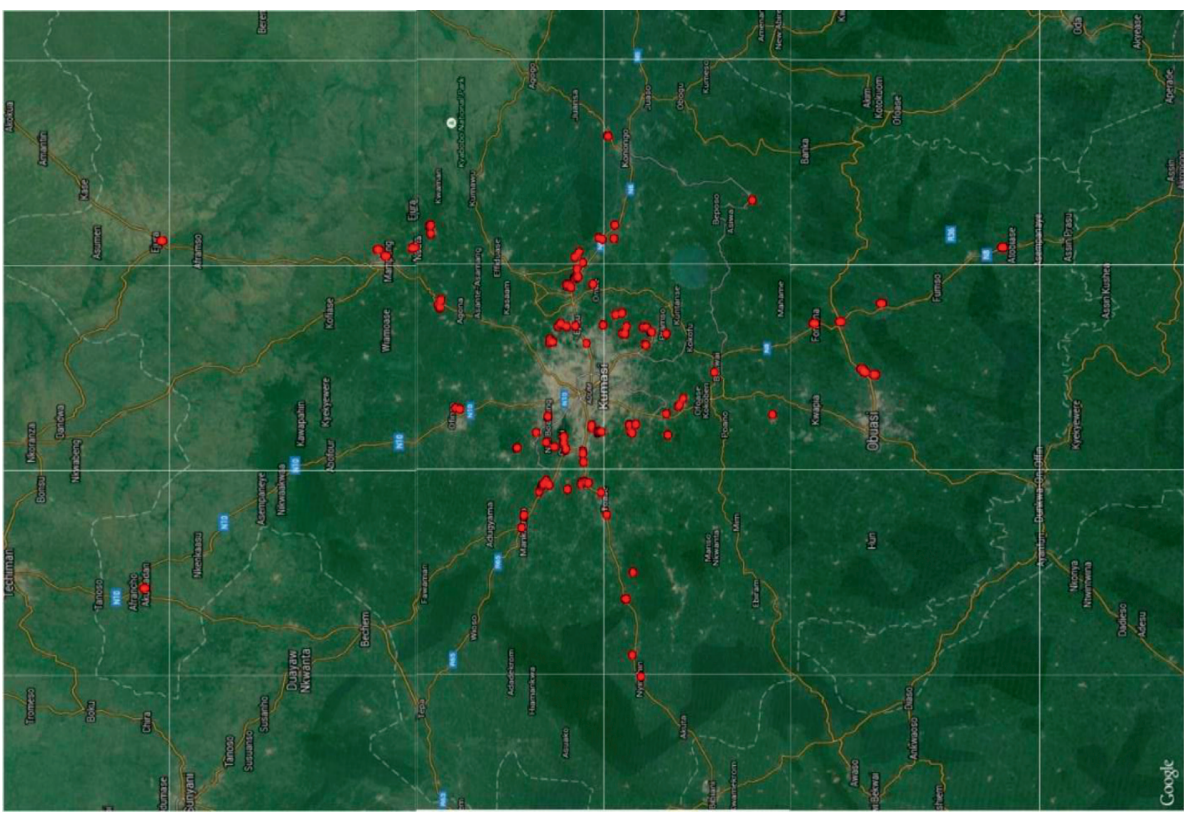

(b)

Figure 1: Continued. 


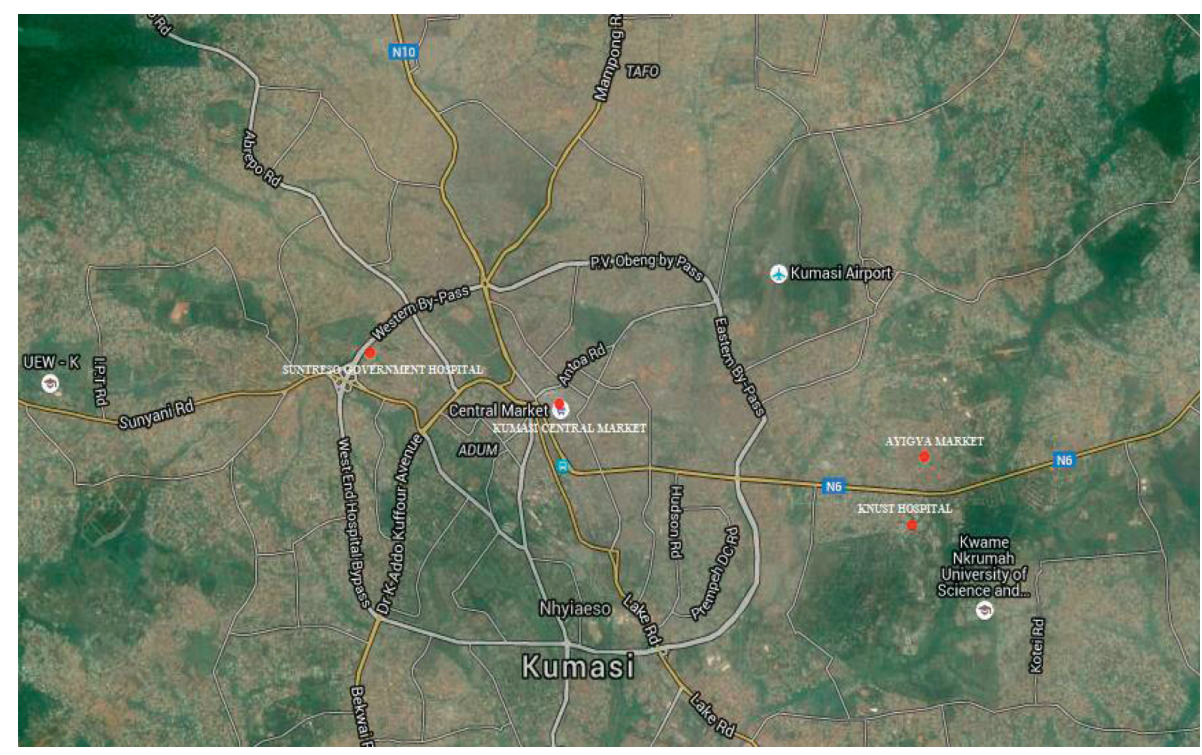

(c)

Figure 1: (a) Map of Ghana showing Ashanti region (study area) with detailed boundaries of all the districts. (b) Distribution of towns in the Ashanti region of Ghana where poultry farms were sampled. (c) Distribution of hospitals and markets in Kumasi where clinical and environmental samples were obtained.

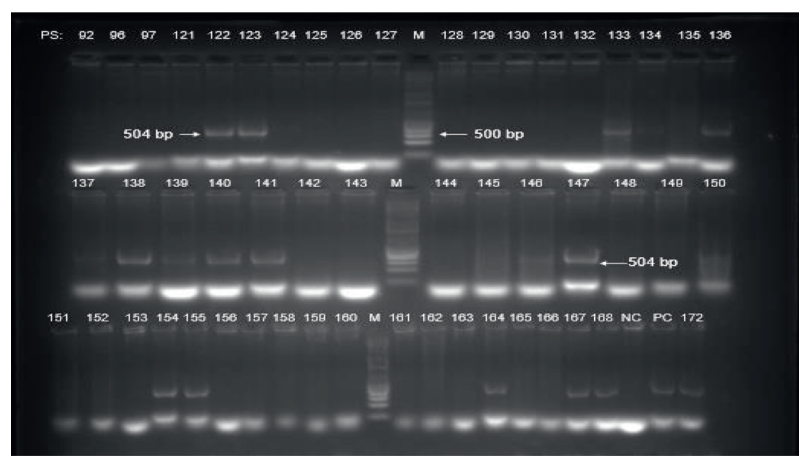

Figure 2: Gel electrophoretic image showing a $504 \mathrm{bp}$ PCR amplicon of a peptidoglycan associated outer membrane lipoprotein gene (oprL) in P. aeruginosa. (M) DNA marker PC: positive control (P. aeruginosa ATCC 27853).

turbidity of the suspensions was then adjusted appropriately to $0.5 \mathrm{McF}$ arland, either by the addition of more colonies or sterile distilled water. A sterile cotton swab was soaked in the inoculum and rotated twice against the inner side of the test tube to remove excess liquid. The swab was used to streak the entire surface of $20 \mathrm{~mL}$ Mueller-Hinton agar (Oxoid, London, $\mathrm{UK}$ ) plate while rotating the plate at an angle of $60^{\circ}$ with repeated streaking (three times in total). With the aid of a disk dispenser, eleven antibiotic disks from six different classes including piperacillin (PIP-100 $\mathrm{g}$, Oxoid Ltd, Basingstoke, UK), ticarcillin (TIC-75 $\mathrm{g}$, Oxoid Ltd, Basingstoke, UK), ceftazidime (CAZ-30 $\mu$ g, Oxoid Ltd, Basingstoke, UK), cefepime (FEP-30 $\mu \mathrm{g}$, Oxoid Ltd, Basingstoke, UK), aztreonam (ATM-30 $\mathrm{g}$, Oxoid Ltd, Basingstoke, UK), imipenem (IPM-10 $\mu$, Oxoid Ltd, Basingstoke, UK), meropenem (MEM-10 $\mathrm{g}$, Oxoid Ltd, Basingstoke, UK), ciprofloxacin (CIP-5 $\mathrm{g}$, Oxoid Ltd,
Basingstoke, UK), gentamycin (CN-10 $\mathrm{g}$, Oxoid Ltd, Basingstoke, UK), levofloxacin (LEV-5 $\mathrm{g}$, Oxoid Ltd, Basingstoke, UK), and ticarcillin/clavulanic acid (TIM$85 \mu \mathrm{g}$, Oxoid Ltd, Basingstoke, UK) were used and incubated at $37^{\circ} \mathrm{C}$ for $24 \mathrm{~h}$ and the mean growth inhibitions and standard deviations calculated. Strains that were resistant to at least one agent from three or more antibiotic classes were identified as multidrug-resistant [15]. P. aeruginosa ATCC 27853 was used as a reference control strain.

2.5. Double Disc Synergy Test (DDST) for Extended Spectrum $\beta$-Lactamase (ESBL) Detection. The DDST is used for the detection of beta-lactamases that are inhibited by betalactamase inhibitors such as clavulanic acid [16]. $20 \mathrm{~mL}$ of Mueller-Hinton agar (Oxoid, London, UK) plates containing $200 \mu \mathrm{g} / \mathrm{mL}$ of cloxacillin was inoculated by swabbing a $1.5 \times 10^{8} \mathrm{cfu} / \mathrm{ml}$ standardized inoculum of $P$. aeruginosa on the surface of the agar using a sterile cotton swab. Amoxicillin-clavulanic acid (20/10) $\mu \mathrm{g}$ disc was placed at the center of the inoculated media. Cefepime $(30 \mu \mathrm{g})$, ceftazidime $(30 \mu \mathrm{g})$, cefotaxime $(30 \mu \mathrm{g})$, ceftriaxone $(30 \mu \mathrm{g})$, imipenem $(10 \mu \mathrm{g})$, and aztreonam $(30 \mu \mathrm{g})$ discs were placed $20 \mathrm{~mm}$ from the central amoxicillin-clavulanate disc. The plates were then incubated at $37^{\circ} \mathrm{C}$ for $24 \mathrm{~h}$. The presence of a "ghost inhibition zone" or a synergistic inhibition of any of the antibiotics towards the central antibiotic was recorded.

2.6. Imipenem-EDTA Synergy Test for Metallo- $\beta$-Lactamase $(M B L)$ Detection. EDTA, a polyaminocarboxylic acid, binds metal ions like zinc and inactivates metallo- $\beta$-lactamases that use zinc to break the amide bond in substrate antibiotics [17]. Imipenem-EDTA synergy test was performed according to the method described by Lee et al. [17]. 
Mueller-Hinton agar $(20 \mathrm{~mL})$ plates were inoculated with $5 \times 10^{8} \mathrm{CFU} / \mathrm{mL}$ of the test organisms. An imipenem disc $(10 \mu \mathrm{g})$ was placed $20 \mathrm{~mm}$ from a blank disk containing $10 \mu \mathrm{L}$ of $0.5 \mathrm{M}$ EDTA (Figure 3(b)). Enhancement of the zone of inhibition in the area between the imipenem and EDTA disks was considered as positive for metallo-beta-lactamase production.

2.7. Phenylboronic Acid Test for KPC Carbapenemase. Phenylboronic acid acts as an inhibitor of the hydrolytic activity of KPC carbapenemases and classes A and C $\beta$-lactamases [18]. P. aeruginosa suspension diluted to 0.5 MacFarland was swabbed on $20 \mathrm{~mL}$ Mueller-Hinton agar and two meropenem discs were placed $30 \mathrm{~mm}$ from each other. $20 \mathrm{~mL}$ of $20 \mathrm{~g} / \mathrm{L}$ phenylboronic acid was added to the second meropenem disc and incubated at $37^{\circ} \mathrm{C}$ for $20 \mathrm{~h}$ (Figure 3(a)). $A \geq 5 \mathrm{~mm}$ increase in inhibition zone of the combined meropenem and phenylboronic acid disc compared to the meropenem disc alone indicated production of KPC carbapenemase enzyme by the P. aeruginosa strain [19].

2.8. D-Test for Detection of Inducible AmpC Beta-Lactamases. The D-test which incorporates an inducer of AmpC enzyme together with a substrate antibiotic as described by Dunne and Hardin [20] was used for the detection of AmpC $\beta$-lactamase production. An antibiotic disc inducing production of AmpC beta-lactamase enzyme (imipenem) was placed between two substrate antibiotic discs (ceftazidime and piperacillin-tazobactam) on an inoculated $20 \mathrm{~mL}$ Mueller-Hinton agar. The plate was incubated for $24 \mathrm{~h}$ at $37^{\circ} \mathrm{C}$. The formation of a D-shaped inhibition zone around any of the substrate discs indicates the imipenem-mediated induction of the AmpC production and the subsequent inactivation of the substrate antibiotic by the $\beta$-lactamase.

2.9. Assessment of Efflux Pump Activity in P. aeruginosa. Ethidium bromide- (EtBr-) agar cartwheel method as described by Martins et al. [21] was used to determine the efflux capacity of the $P$. aeruginosa isolates. Ethidium-bromide (EtBr) intercalates between DNA and produces fluorescence under ultraviolet radiation. It also acts as a substrate for most bacteria efflux pumps. It is thus rapidly pumped out by an overexpressed efflux pump resulting in lack of fluorescence of the bacteria mass [21]. Isolates of $P$. aeruginosa were cultured in $5 \mathrm{~mL}$ of nutrient broth (Oxoid, London, UK) at $37^{\circ} \mathrm{C}$ for $24 \mathrm{~h}$. The optical density (OD) of the cultures was adjusted to $0.5 \mathrm{McF}$ arland. Mueller-Hinton agar $(20 \mathrm{~mL})$ plates containing ethidium bromide at concentrations of 0 to $2.5 \mathrm{mg} / \mathrm{L}$ were divided into sectors to form a cartwheel pattern. The OD adjusted cultures were swabbed on EtBr agar plates from the center to the edge of the plate. Each plate was swabbed with $P$. aeruginosa ATCC 27853 which served as a comparative control. The agar plates were then incubated for $16 \mathrm{~h}$ at $37^{\circ} \mathrm{C}$ and examined under an UV-transilluminator. The minimum concentration of $\mathrm{EtBr}\left(\mathrm{MC}_{\mathrm{EtBr}}\right)$ that produced fluorescence of the bacteria mass after incubation for $24 \mathrm{~h}$ was used in determining the efflux capacity of the various isolates (Figure 3(c)). The capacity of each bacteria strain to efflux EtBr was ranked relative to the reference strain ( $P$. aeruginosa ATCC 27853) by calculating the efflux capacity index $(\sigma)$ :

$$
\sigma=\frac{\mathrm{MC}_{\mathrm{EtBr}(\mathrm{MDR})}-\mathrm{MC}_{\mathrm{EtBr}(R)}}{\mathrm{MC}_{\mathrm{EtBr}(\mathrm{Ref})}}
$$

$\mathrm{MC}_{\mathrm{EtBr}(\mathrm{MDR})}$ is minimum concentration of EtBr which produced fluorescence in MDR $P$. aeruginosa. $\mathrm{MC}_{\mathrm{EtBr}(R)}$ is minimum concentration of EtBr which produced fluorescence in $P$. aeruginosa ATCC 27853. Efflux activity was ranked as very high $\left(\sigma^{* * * *}=7\right.$ to 9$)$, high $\left(\sigma^{* * * *}=4\right.$ to 6$)$, moderate $\left(\sigma^{* * * *}=1\right.$ to 3$)$, and low $\left(\sigma^{* * * *}=0\right)$.

2.10. Detection of $\beta$-Lactamases and Aminoglycoside Modifying Enzyme Encoding Gene. Antibiotic resistance genes encoding some genetic variants of ESBLS $\left(b l a_{S H V 1}, b l a_{T E M 1}\right.$, and $\left.b l a_{C T M X}\right)$, MBLS (bla $a_{V I M}$ and $\left.b l a_{I M P}\right)$, and aminoglycoside modifying enzymes (aac (3)- $I V$ ) were sought in the MDR isolates. Using the forward and reverse primers in Table 1, polymerase chain reaction was carried out using a thermal cycler in a final volume of $25 \mu \mathrm{L}$ containing $2 \mu \mathrm{L}$ of DNA template, $12.5 \mu \mathrm{L}$ of GoTaq Master Mix, $0.75 \mu \mathrm{L}$ of a $0.5 \mathrm{mM}$ magnesium chloride, and $8.55 \mu \mathrm{L}$ of nuclease-free water. The DNA template was initially denatured at $94^{\circ} \mathrm{C}$ for $5 \mathrm{~min}$, followed by 35 cycles of denaturation of $94^{\circ} \mathrm{C}$ for $30 \mathrm{sec}$ and extension of $72^{\circ} \mathrm{C}$ for $1 \mathrm{~min}$. Annealing temperatures for $b l a_{S H V 1}, b l a_{T E M 1}, b l a_{C T M X}, b l a_{V I M}, b l a_{I M P}$, and aac (3) $-I V$ were $56^{\circ} \mathrm{C}$ for $1 \mathrm{~min}, 58^{\circ} \mathrm{C}$ for $1 \mathrm{~min}, 60^{\circ} \mathrm{C}$ for $30 \mathrm{sec}, 51^{\circ} \mathrm{C}$ for $1 \mathrm{~min}, 55^{\circ} \mathrm{C}$ for $1 \mathrm{~min}$, and $50^{\circ} \mathrm{C}$ for $1 \mathrm{~min}$, respectively. Finally, the products were extended at $72^{\circ} \mathrm{C}$ for $10 \mathrm{~min}$. The PCR products were examined on a $2 \% \mathrm{w} / \mathrm{v}$ agarose gel at $60 \mathrm{~V}$ for $120 \mathrm{~min}$ and visualized using a transilluminator.

\subsection{Detection of Integrons in $P$. aeruginosa Isolates.} Bacteria genomic or plasmid DNA may contain antibiotic resistance markers and gene cassettes (integrons) that encode resistance to several antimicrobial agents. In order to determine the prevalence of integrons in the isolates, amplifications of the $5^{\prime}$ conserved (GGCATCCAAGCGCAAG) and $3^{\prime}$ conserved (AAGCAGACTTGACCTGA) regions of class 1 integron and class 2 integrons (with forward and reverse primers int2-F and reverse int2-R) were performed. The reaction conditions were an initial denaturation at $94^{\circ} \mathrm{C}$ for $5 \mathrm{~min}$, further denaturation at $94^{\circ} \mathrm{C}$ for $1 \mathrm{~min}$, annealing at $59.5^{\circ} \mathrm{C}$ for $1 \mathrm{~min}$ (class I integron), and $60^{\circ} \mathrm{C}$ for $1 \mathrm{~min}$ extension of $72^{\circ} \mathrm{C}$ (class 2 integron) for $4 \mathrm{~min}$. The products were finally extended at $72^{\circ} \mathrm{C}$ for $10 \mathrm{~min}$. $5 \mu \mathrm{L}$ of the amplicon was loaded into a 20 -well $1.5 \% \mathrm{w} / \mathrm{v}$ agarose gel in $1 \mathrm{X}$ TAE (1 mM EDTA, $40 \mathrm{mM}$ Tris-acetate) and run for $340 \mathrm{~min}$ at $65 \mathrm{~V}$.

\section{Results and Discussion}

A total of $87 P$. aeruginosa isolates were confirmed from the clinical, environmental, and poultry litter samples. 


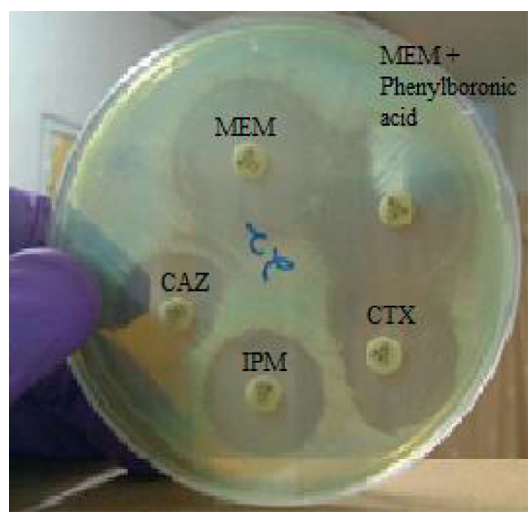

(a)

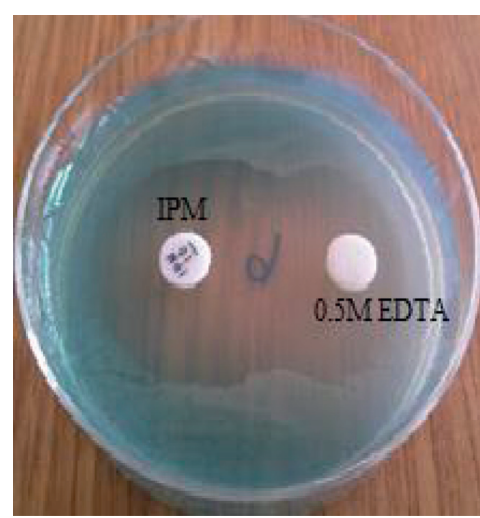

(b)

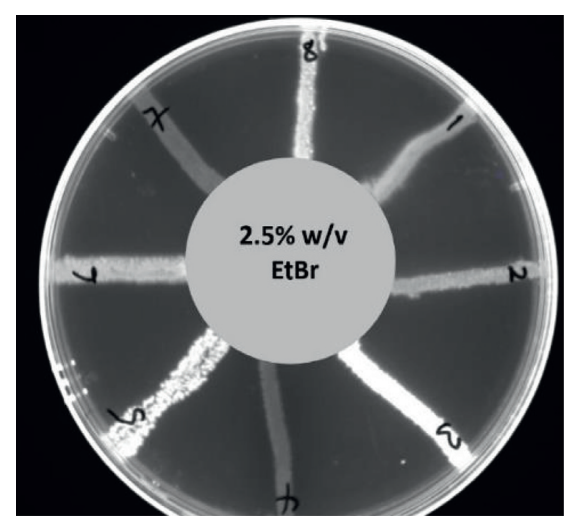

(c)

FIGURE 3: (a) Boronic acid test for detection of KPC-type carbapenemases (no synergy observed in the activity of meropenem in the presence of a KPC enzyme inhibitor-phenylboronic acid); D-test for detection of inducible AmpC $\beta$ - lactamases (D-shaped inhibition zone of substrate antibiotic (ceftazidime and cefotaxime)). (b) Imipenem-EDTA synergy test for detection of metallo- $\beta$-lactamases production (enhancement of imipenem inhibition zone towards EDTA due to MBL inhibitory activity of EDTA). (c) Fluorescence of MDR P. aeruginosa on ethidium bromide incorporated Mueller-Hinton agar plates. IPM: imipenem; MEM: meropenem; CAZ: ceftazidime; CTX: cefotaxime; EDTA: ethylenediaminetetraacetic acid. EtBr: ethidium bromide.

TABLe 1: Primer nucleotide sequences for detection of antibiotic-resistant genes.

\begin{tabular}{|c|c|c|c|c|c|}
\hline Primer & Primer sequence $\left(5^{\prime}-3^{\prime}\right)$ & $\begin{array}{l}\text { Amplicon } \\
\text { size (bp) }\end{array}$ & $\begin{array}{c}\text { Annealing } \\
\text { temperature }\left({ }^{\circ} \mathrm{C}\right)\end{array}$ & Homology & $\begin{array}{c}\text { Reference/ } \\
\text { accession } \\
\text { number }\end{array}$ \\
\hline $\begin{array}{l}\text { oprL-F } \\
\text { oprL-R }\end{array}$ & $\begin{array}{l}\text { ATG GAA ATG CTG AAA TTC GGC } \\
\text { CTT CTT CAG CTC GAC GCG ACG }\end{array}$ & 504 & 64 & $\begin{array}{l}\text { P. aeruginosa } \\
\text { identification }\end{array}$ & [13] \\
\hline $\begin{array}{l}5^{\prime} \mathrm{CS} \\
3^{\prime} \mathrm{CS}\end{array}$ & $\begin{array}{c}\text { GGCATCCAAGC GCAAG } \\
\text { AAG CAG ACT TGA CCT GA }\end{array}$ & Variable & 59.5 & $\begin{array}{l}\text { Conserved region of } \\
\text { class } 1 \text { integron }\end{array}$ & {$[22]$} \\
\hline $\begin{array}{l}\text { Int2-F } \\
\text { Int2-R }\end{array}$ & $\begin{array}{l}\text { CACGGATATGCGACAAAAAGGT } \\
\text { GTAGCAAACGAGTGACGAAATG }\end{array}$ & 788 & 60 & Class 2 integron & {$[23]$} \\
\hline $\begin{array}{l}\operatorname{aac}(3)-I V \\
-F \\
\operatorname{aac}(3)- \\
\text { IV-R }\end{array}$ & $\begin{array}{l}\text { GTGTGCTGCTGGTCCACAGC } \\
\text { AGTTGACCCAGGGCTGTCGC }\end{array}$ & 627 & 50 & $\begin{array}{l}\text { Aminoglycoside } \\
\text { acetyltransferase }\end{array}$ & {$[24]$} \\
\hline $\begin{array}{l}\text { SHV } 1 \\
\text { SHV } 2\end{array}$ & $\begin{array}{c}\text { GGG TTA TTC TTA TTT GTC GC } \\
\text { TTA GCG TTG CCA GTG CTC }\end{array}$ & 900 & 56 & SHV ESBL & {$[25]$} \\
\hline $\begin{array}{l}\text { TEM1-F } \\
\text { TEM1-R }\end{array}$ & $\begin{array}{l}\text { ATG AGT ATT CAA CAT TTC CG } \\
\text { CTG ACA GTT ACC AAT GCT TA }\end{array}$ & 867 & 58 & TEM ESBL & {$[25]$} \\
\hline $\begin{array}{l}\text { CTMX-F } \\
\text { CTMX -R }\end{array}$ & $\begin{array}{c}\text { ATG TGC AGY ACC AGT AAR GTK ATG } \\
\text { GC } \\
\text { TGG GTR AAR TAR GTS ACC AGA AYC } \\
\text { AGC G }\end{array}$ & 593 & 60 & CTMX ESBL & {$[26]$} \\
\hline $\begin{array}{l}\text { VIM-F } \\
\text { VIM -R }\end{array}$ & $\begin{array}{l}\text { ATG GTG TTT GGT CGC ATA TC } \\
\text { TGG GCC ATT CAG CCA GAT C }\end{array}$ & 261 & 51 & VIM MBL & {$[25]$} \\
\hline $\begin{array}{l}\text { IMP -F } \\
\text { IMP- R }\end{array}$ & $\begin{array}{c}\text { CTA CCG CAG AGT CTT TG } \\
\text { AAC CAG TTT TGC CTT ACC AT }\end{array}$ & 600 & 55 & IMP MBL & {$[25]$} \\
\hline
\end{tabular}

Morphologically, all the P. aeruginosa isolates were Gramnegative (Figure 4(a)) unicellular rods appearing as mucoid or nonmucoid colonies. The mucoid form is mainly due to alginate slime formation, which is presumed to play a role in colonization and virulence [27]. Identification of $P$. aeruginosa isolates included identifying the production of the soluble pigments (Figure 4(b)), pyocyanin (blue-green)
[28, 29], fluorescein (greenish-yellow), pyorubin (red) [30], or pyomelanin (reddish-brown) $[31,32]$, growth at $42^{\circ} \mathrm{C}$, and test for catalase production (Figure $4(\mathrm{c})$ ) and $\beta$-haemolysis on blood agar (Figure 4(d)).

$38 P$. aeruginosa strains from clinical, environmental, and poultry litter sources which failed to produce characteristic pigments were identified through oprL gene 


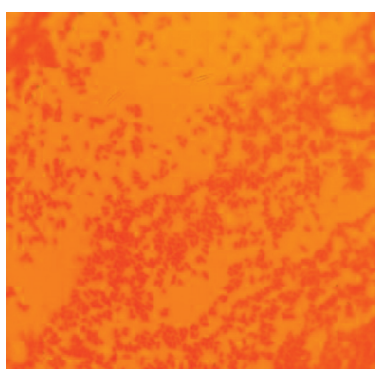

(a)

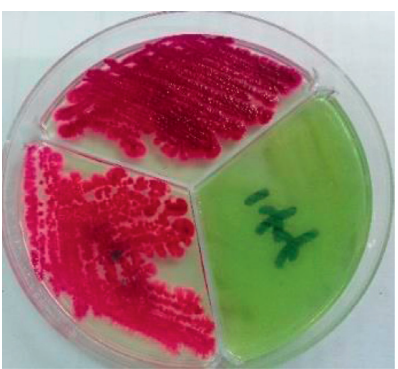

(b)

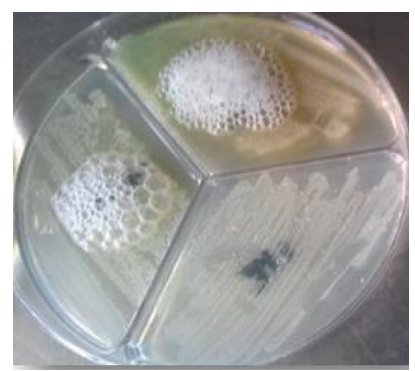

(c)

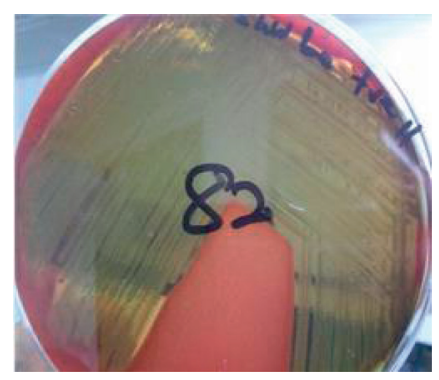

(d)

FIgURE 4: Biochemical characteristics of clinical, environmental, and poultry litter P. aeruginosa isolates. (a) Gram-negative unicellular rods of Pseudomonas aeruginosa. (b) Pigmentation of P. aeruginosa on Pseudomonas isolation agar (Alpha Biosciences, Maryland, USA). (c) Catalase production by $P$. aeruginosa. (d) $\beta$-Haemolysis of $P$. aeruginosa on blood agar.

amplification. This is consistent with reports by De Vos et al. [13] and Douraghi et al. [33] who illustrated the sensitivity of $o p r L$ outer membrane gene amplification in the identification of $P$. aeruginosa from both clinical and environmental sources.

There was low prevalence of $P$. aeruginosa (9.6\%) in the samples collected from the various sources. Of the 900 samples, 162 isolates were identified through culture and biochemical characteristics (Figures 4(a)-4(d)). $P$. aeruginosa isolates from environmental $(13.4 \%, n=35$ / $260)$ and clinical $(12.9 \%, n=47 / 364)$ samples were more prevalent compared to poultry litter $(1.8 \%, n=5 / 276)$ samples. Among the clinical samples, $P$. aeruginosa was highly prevalent in stool $(39.7 \%, n=31 / 78)$ than in urine samples $(15.4 \%, n=15 / 97)$ of patients $(p=0.00077)$ (Table 2). This may be so because, aside from the resident $P$. aeruginosa colonization of the gastrointestinal tract, most ingested food, especially uncooked foods and slightly cooked foods, may be contaminated with $P$. aeruginosa and other pathogenic bacteria [34, 35].

This may increase its colonization of the gastrointestinal tract and hence its high prevalence in stool. All blood samples from the patients did not contain $P$. aeruginosa. The absence of $P$. aeruginosa in the blood samples, however, suggests that patients who took part in the study had no sepsis caused by $P$. aeruginosa. This finding is, however, contrary to a report by Opoku [36], from Komfo Anokye Teaching Hospital in Kumasi, Ghana, in which $11.83 \%$ of 187 samples obtained from blood of patients had $P$. aeruginosa colonization.

$7 \%$ of the confirmed $P$. aeruginosa strains $(n=6)$ of the isolates were sensitive to all antipseudomonal groups studied. 1, 16, and 21 poultry litter, clinical, and environmental isolates of $P$. aeruginosa were multidrug-resistant. From the study, nearly half (43.6\%) of the isolates were resistant to at least three antipseudomonal groups (Figure 5). Comparing these findings to a study by Addo [37] who reported 13.04\% MDR in P. aeruginosa isolates from wounds of patients comparably shows a surge in the number of MDR $P$. aeruginosa strains in the study isolates.

Enzymes that hydrolyze the $\beta$-lactam ring of antibiotics may be extended spectrum $\beta$-lactamases (ESBLS), metallo- $\beta$-lactamase

(MBLS), cephalosporinases (AmpC), or carbapenemases (KPC) [38]; $\beta$-lactamase inhibitors such as clavulanic acid inhibit $\beta$-lactamases produced in bacteria and thus may augment the activity of $\beta$-lactamase substrate antibiotics [39]. They can therefore be used for the detection of enzyme induction in a bacteria species using the double-disc synergy test (DDST). Addition of cloxacillin inhibits the activity of AmpC enzyme [16]. In the study, ESBLs were detected in $84.2 \%(n=32)$ (Table 3$)$ of the MDR P. aeruginosa isolates. Almost 88\% (14/16) of the clinical and $80.9 \%(17 / 21)$ of the environmental MDR $P$. aeruginosa isolates produced ESBLs, indicating high prevalence of these enzymes in both clinical and environmental isolates. The MDR $P$. aeruginosa isolate from poultry litter was also found to produce ESBLs. About $5 \%$ of the study isolates produced no $\beta$-lactamase enzymes. Even though extended spectrum $\beta$-lactamase (ESBL) enzymes were prevalent in $84.2 \%$ of the MDR isolates, only $34.2 \%$ produced only ESBLs. This is similar to the findings of Newman et al. [8] who detected high ESBL production (90 to 98\%) in Gram-negative isolates from the southern, middle, and northern sectors of Ghana. Metallo- $\beta$-lactamase enzymes (MBLs) and inducible AmpC $\beta$-lactamases were detected in $34.2 \%$ and $50 \%$ of the MDR isolates, respectively.

None of the P. aeruginosa isolates produced KPC type carbapenemase enzymes. Coproduction of ESBL, MBL and AmpC was predominant in the isolates with occurrence rates ranging from 21.1 to $44.7 \%$. ESBL and AmpC coproduction was the most prevalent (44.7\%) in the MDR isolate but the carbapenems (meropenem and imipenem) remained effective against these enzyme producers. ESBL producers were also susceptible to carbapenems as reported by Feglo and Opoku [40], and this confirms their role in the definitive treatment of ESBL producing bacteria strain infections. In a related report by Feglo and Opoku [40] on 187 P. aeruginosa isolates from Kumasi, $44.9 \%$ were AmpC producers and $21.9 \%$ were ESBL producers. These findings indicate an increase in both ESBL prevalence and MBL prevalence.

The prevalence of $\mathrm{AmpC}$ was relatively high compared to other study reports in Delhi, India (20.7\%) [41], and MBL prevalence was similar to findings from Brazil which reported $36.4 \% \pm 14.1 \mathrm{MBL}$ occurrence in P. aeruginosa [42]. 
TABLE 2: Sample screened and the number of $P$. aeruginosa isolates obtained.

\begin{tabular}{lccc}
\hline Source of Sample & Total sample $(n=900)$ & Number of isolates $(n=87)$ & Percentage $(\%)$ \\
\hline Clinical & 364 & 47 & 31 \\
Stool & 78 & 15 & 39.7 \\
Urine & 97 & 0 & 15.4 \\
Blood & 100 & 1 & 0 \\
Farm hands & 89 & 35 & 1.1 \\
Environmental & $\mathbf{2 6 0}$ & 12 & $\mathbf{1 3 . 4}$ \\
\hline Sewage & 96 & 15 & 12.5 \\
Market floors & 104 & 8 & 14.4 \\
Others & & & \\
Poultry litter & $\mathbf{2 7 6}$ & $\mathbf{5}$ & 13.3 \\
\hline
\end{tabular}

Others ${ }^{\mathrm{a}}$ : environmental samples collected from market tables, community-based latrines, and water source.

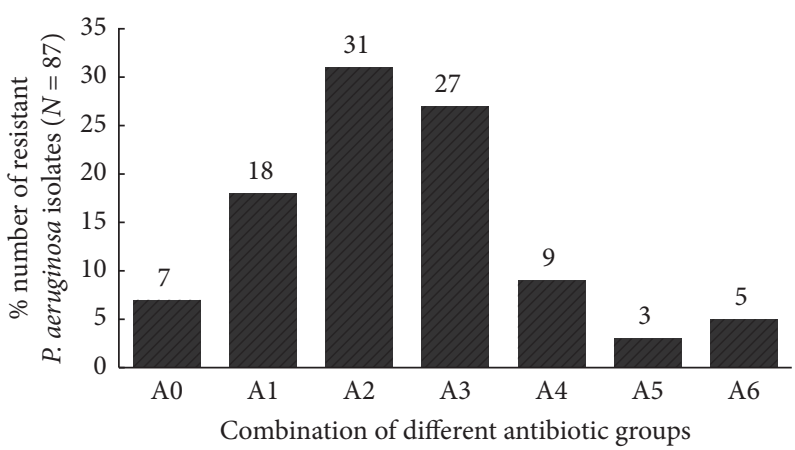

Figure 5: Number of resistant $P$. aeruginosa to the various antipseudomonal groups (quinolones, carbapenem, aminoglycosides, penicillin, cephalosporin, and monobactams). AO: no antibiotic group; A1: one antibiotic group; A2: two antibiotic groups; A3: three antibiotic groups; A4: four antibiotic groups; A5: five antibiotic groups; A6: six antibiotic groups.

These findings could indicate geographical variations in the prevalence of AmpC producing $P$. aeruginosa and may be due to low usage of cephalosporins that induce production of this enzyme.

Genetic variants of common ESBL encoding antibiotic resistance genes $\left(b l a_{S H V}, b l a_{T E M}\right.$, and $\left.b l a_{C T M X}\right)$ were not detected in any of the MDR isolates. The most common MBL encoding genes $\left(b l a_{I M P}\right.$ and $\left.b l a_{V I M}\right)$ were also not detected in any of the isolates. Even though some common $\beta$-lactamase antibiotic-resistant genes were not detected, enzymes that are products of these genes were phenotypically detected in the isolates. This indicates that other $\beta$-lactamase encoding genes such as $b l a_{\mathrm{PER}}, b l a_{\mathrm{VEB}}, b l a_{\mathrm{GES}}, b l a_{\mathrm{PSE}}, b l a_{\mathrm{SPM}}, b l a_{\mathrm{GIM}}$, $b l a_{\mathrm{AIM}}, b l a_{\mathrm{NDM}}, \mathrm{AmpC}$, and $b l a_{\mathrm{OXA}}$, which have been found in $P$. aeruginosa from other geographical regions [38], may be responsible for the regulation of $\beta$-lactamase enzyme production. A similar study by Addo [37], in Korle Bu Teaching Hospital, Accra, and Regional Hospital, Koforidua, Ghana, also found no $b l a_{\mathrm{VIM}}$ and $b l a_{\mathrm{IMP}}$ carbapenemase encoding genes in $P$. aeruginosa strains from diabetic, burn, and cellulitic wounds of patients, suggesting their low prevalence in $P$. aeruginosa in Ghana.

Absence of these ESBL enzyme types could greatly enhance susceptibility of the $P$. aeruginosa strains to $\beta$-lactam substrates such as cephalosporins (ceftazidime, ceftriaxone, and cefepime), monobactams (aztreonam), carboxypenicillins, and ureidopenicillins. The absence of metallo$\beta$-lactamase (carbapenemase) encoding genes, however, suggests that there was no impact of their enzyme variants to carbapenem (meropenem and imipenem) resistance in the $P$. aeruginosa strains isolated.

Circulation of enzyme groups of TEM, SHV, and CTX$\mathrm{M}$ has, however, been detected in many Escherichia coli strains from patients in Komfo Anokye Teaching Hospital, Kumasi, Ghana [40]. IMP-1, IMP-6, IMP-9, VIM-1, VIM3 , and other metalloenzyme variants have also been identified in $P$. aeruginosa isolates from other countries like Japan, China, Singapore, Brazil, Italy, Greece, Taiwan, and Iran [43]. $P$. aeruginosa may gain resistance to aminoglycosides through a series of resistance mechanisms including enzymatic modification [44]. The presence of aminoglycoside resistance gene $A A C$ (3)- $I V$ (resistance to gentamycin, tobramycin, and netilmicin) was determined in both gentamycin-resistant and sensitive MDR $P$. aeruginosa. No $A A C$ (3)- $I V$ gene was detected in any of the MDR $P$. aeruginosa isolates. This rules out the impact of their enzyme variants in strains that were resistant to the studied aminoglycosides. 
Table 3: Prevalence of $\beta$-lactamase enzymes in MDR P. aeruginosa $(n=38)$.

\begin{tabular}{|c|c|c|c|c|c|c|c|c|c|c|c|c|}
\hline \multirow{2}{*}{ Type of $\beta$-lactamase } & \multicolumn{11}{|c|}{ Number of multidrug-resistant $P$. aeruginosa isolates } & \multirow[b]{2}{*}{ ATM } \\
\hline & $n(\%)$ & CIP & LEV & MEM & IPM & $\mathrm{CN}$ & TIC & PIP & TIM & FEP & CAZ & \\
\hline No $\beta$-lactamase & $2(5.3 \%)$ & 2 & & 1 & 1 & 1 & 2 & 1 & 1 & 1 & 2 & $\mathrm{O}$ \\
\hline Only ESBL & $13(34.2 \%)$ & 13 & 7 & 1 & 1 & 13 & 10 & 3 & 5 & 5 & 3 & 4 \\
\hline Only MBL & $2(5.3 \%)$ & 1 & & & & 2 & 1 & & & & & 2 \\
\hline Only AmpC & $2(5.3 \%)$ & 2 & & 1 & & 1 & 1 & 1 & & 1 & & 2 \\
\hline $\mathrm{ESBL}+\mathrm{MBL}$ & $11(28.9 \%)$ & 8 & 5 & 1 & 2 & 8 & 10 & 2 & 3 & & 1 & 2 \\
\hline $\mathrm{ESBL}+\mathrm{AmpC}$ & $17(44.7 \%)$ & 15 & 6 & 2 & 4 & 16 & 14 & 3 & 4 & 3 & 3 & 4 \\
\hline MBL + AmpC & $8(21.1 \%)$ & 8 & 4 & 1 & 1 & 8 & 9 & 2 & 2 & & 1 & 1 \\
\hline $\mathrm{ESBL}+\mathrm{MBL}+\mathrm{AmpC}$ & $9(23.7 \%)$ & 8 & 5 & 1 & 2 & 8 & 9 & 2 & 2 & & 1 & 1 \\
\hline
\end{tabular}

CIP: ciprofloxacin; LEV: levofloxacin; MEM: meropenem; IPM: imipenem; CN: gentamycin; TIC: ticarcillin; TIM: ticarcillin/clavulanic acid; FEP: cefepime; ATM: aztreonam; CAZ: ceftazidime; PIP: piperacillin; N: number of multidrug-resistant isolates; ESBL: extended spectrum $\beta$-lactamase; MBL: metallo$\beta$-lactamase; AmpC: cephalosporinase.

Table 4: Phenotypic and genotypic resistant determinants in P. aeruginosa isolates.

\begin{tabular}{|c|c|c|c|c|c|c|c|}
\hline MDR strain & Source & ESBL & $\mathrm{KPC}$ & MBLS & Inducible AmpC & Efflux capacity index & Class 1 integron \\
\hline $\mathrm{PS}_{196}$ & $\mathrm{E}$ & + & - & - & + & 0 & + \\
\hline $\mathrm{PS}_{204}$ & $\mathrm{E}$ & - & - & + & - & 0 & + \\
\hline $\mathrm{PS}_{170}$ & $\mathrm{E}$ & + & - & - & - & 0 & + \\
\hline $\mathrm{PS}_{205}$ & $\mathrm{E}$ & + & -- & + & + & 0 & + \\
\hline $\mathrm{PS}_{195}$ & E & + & - & - & - & 1 & + \\
\hline $\mathrm{PS}_{197}$ & $\mathrm{E}$ & + & - & - & - & 7 & + \\
\hline $\mathrm{PS}_{168}$ & E & + & - & - & + & 1 & + \\
\hline $\mathrm{PS}_{185}$ & $\mathrm{E}$ & + & - & + & - & 0 & + \\
\hline $\mathrm{PS}_{155}$ & $\mathrm{E}$ & + & - & - & + & 9 & + \\
\hline $\mathrm{PS}_{137}$ & $\mathrm{E}$ & - & - & - & + & 0 & + \\
\hline $\mathrm{PS}_{139}$ & $\mathrm{E}$ & - & - & - & - & 0 & - \\
\hline $\mathrm{PS}_{133}$ & $\mathrm{E}$ & + & - & - & - & 1 & + \\
\hline $\mathrm{PS}_{123}$ & $\mathrm{E}$ & + & - & + & + & 0 & + \\
\hline $\mathrm{PS}_{113}$ & $\mathrm{E}$ & + & - & + & + & 1 & + \\
\hline $\mathrm{PS}_{112}$ & $\mathrm{E}$ & + & - & - & - & 5 & + \\
\hline $\mathrm{PS}_{108}$ & $\mathrm{E}$ & - & - & - & + & 0 & - \\
\hline $\mathrm{PS}_{102}$ & E & + & - & + & + & 1 & + \\
\hline $\mathrm{PS}_{167}$ & E & + & - & + & + & 0 & - \\
\hline $\mathrm{PS}_{105}$ & E & + & - & + & + & 5 & + \\
\hline $\mathrm{PS}_{109}$ & $\mathrm{E}$ & + & - & - & + & 1 & + \\
\hline $\mathrm{PS}_{111}$ & $\mathrm{E}$ & + & - & - & + & 9 & + \\
\hline $\mathrm{PS}_{231}$ & PL & + & - & - & - & 1 & + \\
\hline $\mathrm{PS}_{14}$ & $S$ & + & - & - & + & 0 & - \\
\hline $\mathrm{PS}_{17}$ & $S$ & + & - & + & + & 4 & + \\
\hline $\mathrm{PS}_{31}$ & $S$ & + & - & - & + & 1 & + \\
\hline $\mathrm{PS}_{37}$ & S & - & - & + & - & 0 & + \\
\hline $\mathrm{PS}_{5}$ & $S$ & + & - & - & - & 0 & + \\
\hline $\mathrm{PS}_{25}$ & $S$ & + & - & + & + & 5 & + \\
\hline $\mathrm{PS}_{29}$ & $S$ & + & - & - & - & 0 & + \\
\hline $\mathrm{PS}_{4}$ & S & + & - & - & - & 0 & + \\
\hline $\mathrm{PS}_{1}$ & $S$ & + & - & + & + & 7 & + \\
\hline $\mathrm{PS}_{33}$ & $S$ & + & - & - & - & 1 & + \\
\hline $\mathrm{PS}_{41}$ & S & + & - & + & - & 0 & + \\
\hline $\mathrm{PS}_{82}$ & $\mathrm{U}$ & + & - & - & - & 1 & + \\
\hline $\mathrm{PS}_{84}$ & $\mathrm{U}$ & + & - & - & - & 0 & + \\
\hline $\mathrm{PS}_{85}$ & $\mathrm{U}$ & - & - & - & - & 1 & + \\
\hline $\mathrm{PS}_{98}$ & $\mathrm{U}$ & + & - & - & + & 3 & + \\
\hline
\end{tabular}

+: present; ESBL: extended spectrum beta-lactamase; MBL: metallo-beta-lactamase; S: stool; U: urine; E: environment; PL: poultry litter. 
A total of $57.8 \%$ of the MDR isolates demonstrated moderate to very high efflux pump activity (Table 4 ). This may affirm an overactive efflux of antibiotics from the bacterial cell reducing the activity of the antipseudomonal antibiotics.

\section{Conclusion}

There was low prevalence $(9.6 \%)$ of $P$. aeruginosa in the clinical, environmental, and poultry litter samples from the Ashanti Region of Ghana. There is, however, an appreciable surge in the number of MDR $P$. aeruginosa strains in the clinical and environmental samples. There was high prevalence of ESBLs (84.2\%), MBLs (34.2\%), and inducible cephalosporinase (AmpC) enzymes (50\%) in the $P$. aeruginosa isolates from Ashanti Region of Ghana. Mobile genetic elements (class I integrons) were also highly prevalent $(89.4 \%)$ in the $P$. aeruginosa strains. Antibiotics with activity against $P$. aeruginosa harboring these antibiotic degrading enzymes and resistance integrons should therefore be recommended for clinical treatment of related infections. Routine surveillance of new emerging MDR pathogenic bacteria strains should be undertaken in potential areas of high AMR selection. Also, some research focus should be directed towards the search for anti-infectives with marked activity against multidrug-resistant pathogenic bacteria.

\section{Abbreviations}

PCR: Polymerase chain reaction

ESBL: Extended spectrum $\beta$-lactamase

MBL: Metallo- $\beta$-lactamase

MDR: Multidrug-resistant.

\section{Data Availability}

The data from the research are available in the University Institutional Repository KNUST Space through the following link: http://dspace.knust.edu.gh/handle/123456789/ 10233.

\section{Ethical Approval}

Ethical clearance for the study was obtained from the Committee on Human Research Publications and Ethics (CHRPE), Kwame Nkrumah University of Science and Technology (KNUST), Kumasi, Ghana.

\section{Consent}

Written consent was obtained from farm participants and patients.

\section{Conflicts of Interest}

The authors declare that there are no conflicts of interest.

\section{Authors' Contributions}

HO performed the experimental work and analyzed the experimental data. VEB supervised the experimental work, analyzed the data, and drafted the first manuscript. YDB analyzed the data and revised the first manuscript. CA conceived, designed, and supervised the project and coordinated the writing and revision of the final manuscript. All authors read and approved the final manuscript.

\section{Acknowledgments}

The authors are grateful to the officials and technical staff of the various hospitals within Ashanti Region of Ghana for their cooperation and assistance during this study.

\section{References}

[1] World Health Organization (WHO), Antimicrobial Resistance. Antimicrobial Resistance: Global Report on Surveillance: 3, World Health Organization (WHO), Geneva, Switzerland, 2014.

[2] J. Davies and D. Davies, "Origins and evolution of antibiotic resistance," Microbiology and Molecular Biology Reviews, vol. 74, no. 3, pp. 417-433, 2010.

[3] Centre for Disease Dynamics, Economics and Policy (CDDEP), State of the World's Antibiotics, CDDEP, Washington, DC, USA, 2015.

[4] H. Harbottle, S. Thakur, S. Zhao, D. G. White, and P. Taylor, "Genetics of antimicrobial resistance," Animal Biotechnology, vol. 17, no. 2, pp. 37-41, 2007.

[5] V. L. Kung, E. A. Ozer, and A. R. Hauser, "The accessory genome of Pseudomonas aeruginosa," Microbiology and Molecular Biology Reviews, vol. 74, no. 4, pp. 621-641, 2010.

[6] V. E. Boamah, C. Agyare, H. Odoi, and A. Dalsgaard, "Practices and factors influencing the use of antibiotics in selected poultry farms in Ghana," Journal of Antimicrobial Agents, vol. 2, no. 2, pp. 1-6, 2016.

[7] P. Feglo, Y. Adu-sarkodie, L. Ayisi et al., "Emergence of a novel extended-spectrum- -lactamase (ESBL)-Producing, fluoroquinolone-resistant clone of extraintestinal pathogenic Escherichia coli in Kumasi, Ghana," Journal of Clinical Microbiology, vol. 51, no. 2, pp. 728-730, 2013.

[8] M. J. Newman, R. E. Arhin, E. S. Donkor, M. Gyansa-lutterodt, and W. Mills-Pappoe, "Laboratory-based nationwide surveillance of antimicrobial resistance in Ghana," Infection Drug Resistance, vol. 8, pp. 379-389, 2015.

[9] M. D. Obritsch, D. N. Fish, R. MacLaren, and R. Jung, "Nosocomial infections due to multidrug-resistant Pseudomonas aeruginosa: epidemiology and treatment options," Pharmacotherapy, vol. 25, no. 10, pp. 1353-1364, 2005.

[10] M. Pattison, P. McMullin, J. M. Bradbury, and J. D. Alexander, Poultry Diseases, Saunders Elsevier, Philadelphia, PA, USA, 6th edition, 2008.

[11] K. Poole, L. D. Hazlett, W. State, and E. P. Greenberg, "Pseudomonas aeruginosa: resistance to the max," Frontiers in Microbiology, vol. 2, pp. 65-13, 2011.

[12] H. Odoi, "Isolation and characterization of multi-drug resistant Pseudomonas aeruginosa from clinical, environmental and poultry litter sources in Ashanti Region of Ghana," Master of Philosophy Thesis, Kwame Nkrumah University of Science and Technology, Kumasi, Ghana, 2017. 
[13] D. De Vos, A. Lim Jr., J. P. Pirnay et al., "Direct detection and identification of Pseudomonas aeruginosa in clinical samples such as skin biopsy specimens and expectorations by multiplex PCR based on two outer membrane lipoprotein genes, oprI and oprL," Journal of Clinical Microbiology, vol. 35, pp. 129-1299, 1997.

[14] EUCAST, "The European committee on antimicrobial susceptibility Testing," 2015, https://asmsig.files.wordpress.com/ 2015/11/breakpoint_table_v_4-01-2015.pdf.

[15] A.-P. Magiorakos, A. Srinivasan, R. B. Carey et al., "Multidrug-resistant, extensively drug-resistant and pandrug-resistant bacteria: an international expert proposal for interim standard definitions for acquired resistance," Clinical Microbiology and Infection, vol. 18, no. 3, pp. 268-281, 2012.

[16] M. Georgios, T. Egki, and S. Effrosyni, "Phenotypic and molecular methods for the detection of antibiotic resistance mechanisms in Gram negative nosocomial pathogens," in Trends in Infectious Diseases, pp. 139-162, INTECH Publisher, London, UK, 2014.

[17] K. Lee, Y. S. Lim, D. Yong, J. H. Yum, and Y. Chong, "Evaluation of the hodge test and the imipenem-EDTA double-disk synergy test for differentiating metallo- -Lactamase-Producing isolates of Pseudomonas spp. and acinetobacter spp," Journal of Clinical Microbiology, vol. 41, no. 10, pp. 4623-4629, 2003.

[18] A. Tsakris, I. Kristo, A. Poulou et al., "Evaluation of boronic acid disk tests for differentiating KPC-possessing Klebsiella pneumoniae isolates in the clinical laboratory," Journal of Clinical Microbiology, vol. 47, no. 2, pp. 362-367, 2009.

[19] S. Pournaras, A. Poulou, and A. Tsakris, "Inhibitor-based methods for the detection of KPC carbapenemase-producing Enterobacteriaceae in clinical practice by using boronic acid compounds," Journal of Antimicrobial Chemotherapy, vol. 65, no. 7, pp. 1319-1321, 2010.

[20] W. M. Dunne Jr. and D. J. Hardin, "Use of several inducer and substrate antibiotic combinations in a disk approximation assay format to screen for AmpC induction in patient isolates of Pseudomonas aeruginosa, Enterobacter spp., Citrobacter spp., and Serratia spp," Journal of Clinical Microbiology, vol. 43, no. 12, pp. 5945-5949, 2005.

[21] M. Martins, M. Viveiros, I. Couto et al., "Identification of efflux pump-mediated multidrug-resistant bacteria by the ethidium bromide-agar cartwheel method," In vivo (Athens, Greece), vol. 25, no. 2, pp. 171-178, 2011.

[22] P. Severino and V. D. Magalhães, "The role of integrons in the dissemination of antibiotic resistance among clinical isolates of Pseudomonas aeruginosa from an intensive care unit in Brazil," Research in Microbiology, vol. 153, no. 4, pp. 221-226, 2002.

[23] D. Mazel, B. Dychinco, V. A. Webb, and J. Davies, “Antibiotic resistance in the ECOR collection: integrons and identification of a novel aad gene," Antimicrobial Agents and Chemotherapy, vol. 44, no. 6, pp. 1568-1574, 2000.

[24] J. Harel, H. Lapointe, A. Fallara et al., "Detection of genes for fimbrial antigens and enterotoxins associated with Escherichia coli serogroups isolated from pigs with diarrhea," Journal of Clinical Microbiology, vol. 29, no. 4, pp. 745-752, 1991.

[25] C. Ratkai, Characterization of medically important Pseudomonas aeruginosa isolates, pp. 1-62, Institute of Clinical Microbiology, Faculty of Medicine University of Szeged, Szeged, Hungary, 2011, Doctor of Philosophy (Ph.D) thesis.

[26] H.-J. Monstein, A. Östholm-balkhed, M. V. Nilsson, M. Nilsson, K. Dornbusch, and L. E. Nilsson, "Multiplex PCR amplification assay for the detection ofblaSHV, blaTEM
andblaCTX-M genes inEnterobacteriaceae,” Apmis, vol. 115, no. 12, pp. 1400-1408, 2007.

[27] K. Todar, "Pseudomonas and related bacteria," in Todar's Online Textbook of BacteriologyUniversity of WisconsinMadison, Madison, WI, USA, 2004, http:// textbookofbacteriology.net/pseudomonas.html.

[28] D. Kanner, N. N. Gerber, and R. Bartha, "Pattern of phenazine pigment production by a strain of Pseudomonas aeruginosa," Journal of Bacteriology, vol. 134, no. 2, pp. 690-692, 1978.

[29] M. Z. El-Fouly, A. M. Sharaf, A. A. M. Shahin, H. A. El-Bialy, and A. M. A. Omara, "Biosynthesis of pyocyanin pigment by Pseudomonas aeruginosa," Journal of Radiation Research and Applied Sciences, vol. 8, no. 1, pp. 36-48, 2015.

[30] S. A. Kandela, A. S. Al-Shibib, and B. H. Al-Khayat, "A study of purified pyorubin produced by local Pseudomonas aeruginosa," Acta Microbiologica Polonica, vol. 46, pp. 37-43, 1997.

[31] E. Yabuuchi and A. Ohyama, "Characterization of "Pyomelanin"-Producing strains of Pseudomonas aeruginosa," International Journal of Systematic Bacteriology, vol. 22, no. 2, pp. 53-64, 1972.

[32] V. T. Orlandi, L. Chiodaroli, T. Tolker-Nielsen, F. Bolognese, and P. Barbieri, "Pigments influence the tolerance of Pseudomonas aeruginosa PAO1 to photodynamically induced oxidative stress," Microbiology, vol. 161, no. 12, pp. 2298-2309, 2015.

[33] M. Douraghi, F. Ghasemi, M. M. Dallal, M. Rahbar, and A. Rahimiforoushani, "Molecular identification of Pseudomonas aeruginosa recovered from cystic fibrosis patients," Journal of Preventive Medicine and Hygiene, vol. 55, no. 2, pp. 50-53, 2014.

[34] P. Mensah, D. Yeboah-Manu, K. Owusu-Darko, and A. Ablordey, "Street foods in Accra, Ghana: how safe are they? Bull," World Health Organ, vol. 80, no. 7, pp. 546-554, 2002.

[35] P. Feglo and K. Sakyi, "Bacterial contamination of street vending food in Kumasi, Ghana," Journal of Medical and Biomedical Sciences, vol. 1, no. 1, pp. 1-8, 2012.

[36] S. Opoku, "AmpC beta-lactamase production among Pseudomonas aeruginosa and Proteus mirabilis clinical isolates at Komfo Anokye teaching hospital in Kumasi, Ghana," pp. 184, Kwame Nkrumah University of Science and Technology, Kumasi, Ghana, 2013, Master's thesis.

[37] F. A. Addo, "Characterization of antimicrobial resistant Pseudomonas Spp and other bacteria from infected wound," pp. 1-72, University of Ghana, Accra, Ghana, 2015, Master of Philosophy thesis.

[38] T. Strateva and D. Yordanov, "Pseudomonas aeruginosa-a phenomenon of bacterial resistance," Journal of Medical Microbiology, vol. 58, no. 9, pp. 1133-1148, 2009.

[39] X. Jiang, Z. Zhang, M. Li, D. Zhou, F. Ruan, and Y. Lu, "Detection of extended-spectrum $\beta$-lactamases in clinical isolates of Pseudomonas aeruginosa," Antimicrobial Agents and Chemotherapy, vol. 50, no. 9, pp. 2990-2995, 2006.

[40] P. Feglo and S. Opoku, "AmpC beta-lactamase production among Pseudomonas aeruginosa and Proteus mirabilis isolates at the Komfo Anokye teaching hospital, Kumasi, Ghana," Journal of Microbiology and Antimicrobials, vol. 6, pp. 13-20, 2014.

[41] V. Manchanda and N. P. Singh, "Occurrence and detection of AmpC beta-lactamases among Gram-negative clinical isolates using a modified three-dimensional test at Guru Tegh Bahadur Hospital, Delhi, India," Journal of Antimicrobial Chemotherapy, vol. 51, no. 2, pp. 415-418, 2003. 
[42] A. P. Zavascki, L. Z. Goldani, A. L. S. Goncalves, A. F. Martins, and A. L. Barth, "High prevalence of metallo- $\beta$-lactamasemediated resistance challenging antimicrobial therapy against Pseudomonas aeruginosa in a Brazilian teaching hospital," Epidemiology and Infection, vol. 135, no. 2, pp. 343-345, 2007.

[43] T. Strateva and D. Yordanov, "Pseudomonas aeruginosa-a phenomenon of bacterial resistance," Journal of Medical Microbiology, vol. 58, pp. 1133-1148, 2016.

[44] G. Meletis and M. Bagkeri, "Pseudomonas aeruginosa: multidrug-resistance development and treatment options," Infection Control, vol. 2, pp. 34-45, 2013. 